\title{
8. Measuring innovation across economic sectors
}

\subsection{INTRODUCTION}

In Part III, Chapter 6 introduced the general definition of innovation, applicable in all economic sectors, and Chapter 7 provided the definitions of the economic sectors in the System of National Accounts (SNA). This led to a discussion of sector-specific innovation. In Chapter 8, the goal is to examine innovation that can occur in any of the SNA sectors. This raises some problems, but it leads to measurement challenges for future work, including how to develop policy for innovation that can happen everywhere.

In the examples which follow, the general definition is applicable. They are: innovation in the informal economy; ecological innovation (eco-innovation); and innovation involving general purpose technologies and practices. The general purpose technology section includes a discussion of user innovation in any sector.

While the three examples of innovation can be specified by the general definition, there are cases where this does not work. An example is 'social innovation'. It is policy relevant and the subject of an extensive policy and research literature, but the approaches to the subject are different and the definitions of social innovation diverse. This will be discussed briefly along with the difference between definitions that support discussion and theorising, introduced in Chapter 6 (Section 6.3), and the general definition which supports the measurement of innovation and the review of innovation policy.

\subsection{INNOVATION IN THE INFORMAL ECONOMY}

The informal economy (or sector) is present in every country and more so in developing countries. The term 'sector' does not correspond to 
sectors used in the SNA to cover all of the economy sectors (EC et al. 2009: para. 25.37). The informal aspects of the economy are discussed in Chapter 25 of the SNA. Chapter 25 also includes the International Labour Organization (ILO) definition of the informal sector from the 15th International Conference of Labour Statisticians (ICLS); the 'informal sector' is a subset of household unincorporated enterprises (EC et al. 2009, para. 25.36).

In addition to understanding informal production, the distinction between formal and informal employment is also relevant ( $\mathrm{EC}$ et al. 2009: para. 25.54) and plays a key role in the statistical measurement of the informal sector. Charmes $(2016,2019)$ describes the use of employment surveys to identify informal units. A survey of the units may then follow to gather information on informal activities.

The interest here is in the statistical measurement of innovation in the informal sector. Charmes (2019) has reviewed the last 50 years of conceptualisation and measurement of the informal sector. Survey methods are also reviewed in Charmes et al. (2018). Charmes (2016) and Charmes et al. (2016) discuss how and where questions on innovation could be inserted into existing economic surveys of households and firms. One of the approaches is to consider to what extent questions from the EU Community Innovation Survey (CIS) can be used in surveys of innovation in the informal economy and what new questions could be added and others removed (Charmes 2016; Charmes et al. 2016). The advantage of this approach is that the statistical measurement of the informal sector, and innovation in the (formal) business sector, are well established with well-tested questions, questionnaires and survey methodology. Bringing both together, while removing questions which do not fit is a first step to a comprehensive measurement programme. The next step is to use the data resulting from surveys to produce indicators that can support policy development.

A new step, made possible by the general definition of innovation, is to replace 'introduced on the market' from the business sector definition of innovation by 'made available to potential users'. Once this is done, questions can be posed about product innovations that are made available at non-economically significant prices, including zero prices. This is important as actors in the informal sector may transfer product innovations for cultural, religious or social reasons that have nothing to do with the market. The general definition of innovation makes possible the gathering of data, providing indicators for monitoring and evaluating innovation policy in the informal economy. 


\subsection{ECO-INNOVATION}

While countries look to innovation to provide jobs and economic growth, there is interest not just in innovation but in eco-innovation leading to a green economy. An example is the European Union green.eu project and the Maastricht Manual on Measuring Eco-Innovation for a Green Economy (Kemp et al. 2019). The project recognises the urgency of having robust statistical measurement of eco-innovation to support international comparisons as countries move towards green economies. The Maastricht Manual goes beyond a standard statistical manual to discuss policies for eco-innovation and the green economy. This includes the measurement of the effect of implemented policies and the monitoring and evaluation of the policies.

Eco-innovation is a means of moving towards a greener economy, making the world a better place, but the development of effective policy that leads to this requires robust and internationally comparable statistical indicators to guide policy development and to monitor and evaluate policies that have been implemented. To achieve this, there must be guidelines for the statistical measurement of eco-innovation. The Maastricht Manual is a significant step towards having official statistics on eco-innovation that can support research on eco-innovation.

The Maastricht Manual encourages the measurement community, statistical offices and research institutes, to add statistical measurements of eco-innovations, and their outcomes, to their official statistics. Official statistics are important because they are credible and support informed public discourse on environmental priorities and the allocation of resources to implementing more effective green policies. In addition to setting standards for data collection and interpretation the Maastricht Manual educates the reader, encourages the use of the data and indicators and should help to build communities of practice that are trying to contribute to the green economy.

This manual is not an end but a beginning. The OECD Working Party of National Experts on Science and Technology Indicators (NESTI) spent many years in discussion before its collective knowledge of innovation was first codified in the Oslo Manual of 1992. Once the manual existed, statisticians, researchers, policy analysts and policy makers learned from collecting and using statistics on innovation and applied that knowledge to revise the manual which is now in its fourth edition (OECD/Eurostat 2018). 
Eco-innovation can happen everywhere, in the public sector, the government sector, the business sector, the private non-profit sector serving households and the household sector. In the past, the interest has been focused on the business sector, but now the Oslo Manual provides a general definition of innovation applicable in all sectors. This applies, as well, to eco-innovation. The definition of eco-innovation is the following:

An eco-innovation is a new or improved product or practice of a unit that generates lower environmental impacts, compared to the unit's previous products or practices, and has been made available to potential users (product) or brought into use by the unit (process). (Kemp et al. 2019: Chapter 2)

The definition is close to that of the general definition in the fourth edition of the Oslo Manual (OECD/Eurostat 2018: para. 2.99) and it is restricted (see Chapter 6) by the addition of 'that generates lower environmental impacts'. The closeness of the definition of eco-innovation to the general definition of innovation provides a link to the broader innovation community and NESTI. It also raises a question about the institutional home for the eco-innovation community as this is where participants can share knowledge gained by doing surveys and analysing the resulting data. In time, this could provide the basis for the next revision of the manual.

The Maastricht Manual is a new tool for studying eco-innovation, for learning about this activity, and supporting policy that can lead to a greener economy.

\subsection{TECHNOLOGIES, PRACTICES AND INNOVATION}

This section examines general purpose technologies and their relationship to innovation in any economic sector.

\subsubsection{General Purpose Technologies and Practices}

A general purpose technology is generic and can be used in many applications. Such technologies have appeared in industrial revolutions in the past: the steam engine; electricity; mass production; and ICT. There is now a suggestion that the fourth industrial revolution (Schwab 2017,2018 ) is happening at a time when the world is threatened by 
climate change, economic and social inequality, and challenged by the Sustainable Development Goals.

General purpose technologies of today, such as digitalisation, artificial intelligence (AI), robotics, the internet of things and the use of big data are moving quickly. The interest 20 years ago was in the access to the internet, the web, and the use of the web to inform clients of available products. Later, the questions concerned e-commerce on the web, both buying and selling. A significant difference is that 20 years ago everything that took place on the web was programmed, by people, whereas now AI is used to find patterns in (big) data, to make decisions and to revise code in apps. Technologies are not just goods related, they can include services and practices such as business models, knowledge management and the use of value and supply chains.

There is also a change in how innovation is managed in the business sector (OECD 2019a). Previously product innovation took place when a new or improved product was introduced on the market, at market prices. Now there are new or improved products offered for zero price, discussed in Chapter 6, Section 6.3. They are still product innovations, but the difference is that these zero price products, in many cases, connect the producer and the user, allowing information about the user to be captured by the producer. Examples are apps, email accounts, access to the iCloud and electronic hubs for trading or other activities. This is a radical change in the business sector, and it can happen in all of the other SNA sectors where institutional units can be users or producers of product innovations. The flow of information from users to producers can be used to make potential users aware of similar products or to suggest alternatives. Such information can also be misused.

So far, only technologies have been discussed, but the same discussion can apply to services and practices, such as knowledge management practices (Foray and Gault 2003) or organisational practices.

General purpose technologies can also be combined to do new things, and this is evident in the digital economy. These activities are not limited to the business sector; they can be used to innovate in any sector. Technologies, general purpose, or more specific, can give rise to process innovation, with implications for user innovation.

\subsubsection{Process Innovation and User Innovation}

From a measurement perspective there are two things to consider when dealing with process innovation. The first is that process innovation can 
occur in an institutional unit if the unit acquires, and brings into use, a product that is, from the perspective of the unit, new or improved and differs significantly from the unit's previous processes. This process innovation draws upon products first developed by other institutional units, with little or no additional modification (OECD/Eurostat 2018: para. 3.14, generalised). In the business sector, this process innovation by acquisition (purchase, rental or leasing) of 'off-the-shelf technologies' is distinguished from user innovation (Gault 2016).

'User innovation' occurs when the institutional unit acquires a product for use and then modifies it to serve better the purposes of the institutional unit. A second type of user innovation occurs when the institutional unit cannot find the technology, or practice, that is needed, and it adopts the technology or practice by developing it for its own use (Gault 2016).

\subsubsection{Policy}

This is a measurement chapter but the use of general purpose technology can influence policy. There are three levels of innovation policy to consider. The first is the acquisition of products that are new or improved to the institutional unit and which allow the institutional unit to be classified as a process innovator. The acquisition can range from procurement policy in public institutions to acquisition by small household unincorporated enterprises. Policy will vary from sector to sector, but the policy maker may wish to promote the acquisition and use of general purpose technologies, such as broadband web access to support electronic commerce anywhere in the country, assuming the infrastructure is in place to support it.

As institutional units will acquire products that are readily available and are new or improved from the perspective of the institutional unit, any statistical measurement would expect to show that a high percentage of institutional units qualify as innovative, based on their acquisitions.

As already discussed, institutional units can acquire products and modify them to meet their own requirements better, or they can develop such products for their own use if they are not readily available. These are cases of user innovation and policy can support this and other types of innovation by promoting the training of workers, by encouraging links to education or research institutions to make use of the knowledge and experience that can be found there, or to encourage collaboration by institutional units. 


\section{$8.5 \quad$ SOCIAL INNOVATION}

Social innovation is a subject of policy interest and it covers a wide range of topics, including social value and ethics. There are no comparable official statistics based on an internationally accepted definition. The definition of innovation for measurement purposes in the fourth edition of the Oslo Manual is not normative and it does not address value or ethics unless these are imposed as a restriction (Chapter 6, Section 6.3).

An example of the range of definitions is provided by Balamatsias (in 2018 ) in the Social Innovation Blog of the Social Innovation Academy where the 'eight most popular definitions' are listed.] None of the eight definitions are designed to support statistical measurement and all include expected outcomes as part of the definition. The European Commission, as part of its innovation policies, provides a definition of social innovation. Social innovations are:

new ideas that meet social needs, create social relationships and form new collaborations. These innovations can be products, services or models addressing unmet needs more effectively.

The difficulty of defining social innovation is illustrated by Moulaert et al. (2013: 15), Moulaert and MacCallum (2019), Nicholls and Murdock (2012) and by Rüede and Lurtz (2012).]

Mulgan (2007:8) provides the following definition. Social innovation comprises:

innovative activities and services that are motivated by the goal of meeting a social need and that are predominantly developed and diffused through organisations whose primary purposes are social.

As an example of applying this definition, consider the 'Delayed transfers of care' statistics in the UK (House of Commons Library Briefing Paper 2019). The issue is that patients are in the wrong care setting which can arise when care settings managed by the social services, or the local government, lack the capacity to transfer patients from hospitals to social service care settings. The policy intervention could be an integration of social services and hospital care services to support planning and resource allocation with a view to moving more people to the right care setting at the right time. 
The implementation of the policy could involve new or improved services made available to potential users, those responsible for the care facilities, and a new or improved process involving management and planning brought into use by the institutional units, in this case the hospital and the social services. There is no guarantee that the desired improvement will happen, but its presence can be confirmed by observation (surveys or administrative data) and change can be monitored over time and comparisons made with other jurisdictions where the policy has been implemented and those where it has not.

This example is chosen as it could be used to support measurement but with a definition of 'innovation', qualified by the word 'social', and of 'innovative activities' which could correspond to innovation activities in the fourth edition of the Oslo Manual (OECD/Eurostat 2018: 247). The definitions diverge when an expectation is added 'meeting a social challenge' as well as the means of diffusion, 'through organizations whose primary purposes are social'. This suggests that the definition of Mulgan et al. (2007) fits into the category introduced in Chapter 6 (Section 6.3), as a definition 'to guide discussion and theorising' which is an important part of developing the subject, in this case, social innovation. The question is whether the social innovation community sees a need for statistical measurement leading to monitoring and evaluation in social innovation policy in any economic sector.

Going back to business sector innovation, at least a decade was spent experimenting with surveys of technological innovation before the community could agree on a definition of innovation and how product or process innovation could be measured in the manufacturing sector (OECD 1992). It could be argued that social innovation is considerably more complex than innovation in manufacturing and it will take longer to build a consensus on measurement. Missing in this process is the equivalent of NESTI which, in consultation with Eurostat, oversees innovation manuals and their revision. In addition, the measurement of the activity of social innovation may not be encouraged. Murray et al. (2010: 6) note that 'Measuring success in the social economy is particularly problematic' and then go on to explain why. Another approach is taken by Marée and Mertens (2012) when discussing the measurement of the performance of social innovation.

The importance of statistical measurement of social innovation, as with the other types of innovation discussed in this chapter, is that the resulting indicators support policy development and then provide a basis for monitoring the implemented policy. Not discussed in this chapter, but 
also important, is the way the growing digital economy is influencing innovation of all kinds, including social innovation. This is discussed in Part IV.

\subsection{CONCLUSION}

This chapter has examined challenges of measuring innovation in the informal economy, eco-innovation, and innovation driven by technologies and practices, both generic and more specific. The general definition of innovation makes it easier to measure the presence of innovation in any economic sector, whether or not the innovation is sector specific (e.g., public sector innovation) or potentially present in all sectors (e.g., green innovation). Social innovation is presented as a work in progress where the general definition does not yet apply, and it may be some time before there are robust measures of social innovation showing change over time and providing a basis for comparison across countries.

Chapters 6, 7 and 8 have examined the measurement of innovation in all sectors of the economy, either sector specific or occurring in any sector. The next task is to see how the general definition can be applied to global challenges, how measurement challenges can be overcome, and how both relate to policies.

\section{NOTES}

1 See Lipsey et al. (2005) on general purpose technology and its application.

1 See https://ec.europa.eu/eurostat/cache/metadata/en/isoc_se_esms.htm (accessed 17 March 2020) and note that the ICT sector includes goods producing industries and services producing industries.

3. See Mulgan et al. (2013) and Mulgan (2019) on measuring social value.

4. See Moulaert et al. (2013) and Howaldt et al. (2014) for an overview of the subject and a critical view of the literature.

5. http://www.socialinnovationacademy.eu/8-popular-social-innovation -definitions/ (accessed 17 March 2020).

6. See https://ec.europa.eu/growth/industry/innovation/policy/social_en (accessed 17 March 2020).

6. Other work on social innovation can be found at: https://www.siceurope.eu/ about-sic/what-socil-innovation/what-social-innovation (accessed 17 March 2020).

8. International comparison may not be an objective of all social innovation communities. The author attended a parallel session of participants in a social innovation conference and asked about establishing baselines and monitoring policy intervention. He was told that, as he was clearly not committed to the cause, he would find another session more to his liking. 